\title{
Localized neuropathic pain: an expert consensus on local treatments
}

This article was published in the following Dove Press journal:

Drug Design, Development and Therapy

13 September 2017

Number of times this article has been viewed

\section{Gisèle Pickering ${ }^{1-3}$ \\ Elodie Martin ${ }^{1,3}$ \\ Florence Tiberghien ${ }^{4}$ \\ Claire Delorme ${ }^{5}$ \\ Gérard Mick ${ }^{6,7}$}

'Centre de Pharmacologie Clinique, $\mathrm{CHU}$ Clermont-Ferrand, ${ }^{2}$ Inserm, $\mathrm{CIC}$ 1405, Neurodol I 107, ${ }^{3}$ Laboratoire de Pharmacologie, Faculté de Médecine, Clermont Université, ClermontFerrand, ${ }^{4}$ Centre d'Evaluation et de Traitement de la Douleur, CHU Jean Minjoz, Besançon, ${ }^{5}$ Centre d'Evaluation et Traitement de la Douleur, Bayeux, 'Unité d'Evaluation et Traitement de la Douleur, Voiron, ${ }^{7}$ Laboratoire AGEIS, Université Grenoble Alpes, Grenoble, France
Correspondence: Gisèle Pickering Clinical Pharmacology Centre, Bâtiment 3C, CHU, Hopital G Montpied, 6300 I Clermont-Ferrand, France

Tel +33473178416

Fax +33473178412

Email gisele.pickering@udamail.fr
Background: Pain localization is one of the hallmarks for the choice of first-line treatment in neuropathic pain. This literature review has been conducted to provide an overview of the current knowledge regarding the etiology and pathophysiology of localized neuropathic pain (LNP), its assessment and the existing topical pharmacological treatments.

Materials and methods: Literature review was performed using Medline from 2010 to December 2016, and all studies involving LNP and treatments were examined. A multidisciplinary expert panel of five pain specialists in this article reports a consensus on topical approaches that may be recommended to alleviate LNP and on their advantages in clinical practice.

Results: Successive international recommendations have included topical 5\% lidocaine and $8 \%$ capsaicin for LNP treatment. The expert panel considers that these compounds can be a first-line treatment for LNP, especially in elderly patients and patients with comorbidities and polypharmacy. Regulatory LNP indications should cover the whole range of LNP and not be restricted to specific etiologies or sites. Precautions for the use of plasters must be followed cautiously. Conclusion: Although there is a real need for more randomized controlled trials for both drugs, publications clearly demonstrate excellent risk/benefit ratios, safety, tolerance and continued efficacy throughout long-term treatment. A major advantage of both plasters is that they have proven efficacy and may reduce the risk of adverse events such as cognitive impairment, confusion, somnolence, dizziness and constipation that are often associated with systemic neuropathic pain treatment and reduce the quality of life. Topical modalities also may be used in combination with other drugs and analgesics with limited drug-drug interactions.

Keywords: neuropathic pain, topical, localized, medicated plaster, patch, review

\section{Introduction}

Neuropathic pain (NP), defined by the International Association for the Study of Pain (IASP) as "pain arising as a direct consequence of a lesion or disease affecting the somatosensory system," 1,2 originates after injury to the central and/or peripheral nervous systems. The mechanisms involved in NP are complex and involve both peripheral and central pathophysiological phenomenon, cross talk between $\mathrm{A}$ and $\mathrm{C}$ fibers and sensitization after injury, formation of ectopic neuronal pacemakers with abnormal or dysfunctional sodium channels, expression of novel ion channels or receptors, activation of several signaling pathways that mediate the induction and maintenance of NP through transcriptional and posttranslational mechanisms. ${ }^{3} \mathrm{NP}$ negatively impacts the quality of life and aggravates functional decline. ${ }^{4,5}$ It is characterized by clinical manifestations that are present across different NP conditions, and its prevalence is nearly $10 \%$ in the general population. ${ }^{6}$

Localization of NP may be restricted to a small and easily identified area (eg, distal part of a dermatoma in postherpetic neuralgia [PHN] or a limited area of the 
knee after prosthetic joint replacement) or may affect a wide region (hemibody in post-stroke central pain). The localized character of NP is more difficult to define when pain is distributed distally or progresses with the natural history of the causal disease, as in diabetic polyneuropathy (DPN) ${ }^{7}$ or chemotherapy-induced neuropathy. ${ }^{8}$ Localized NP (LNP) is the most common presentation of NP, affecting about $60 \%$ of NP patients. ${ }^{9}$ Pharmacotherapy is the recommended first-line treatment, and international guidelines are regularly published. ${ }^{10-13}$ Although topical agents such as lidocaine or capsaicin are widely used for peripheral NP, the literature does not clearly define the "localized" NP for which they are recommended, and the clinical characteristics of patients for whom a topical approach should be recommended are poorly described. A core definition of LNP was proposed by an expert group to help clinicians better characterize LNP, ${ }^{14}$ and pain localization is one of the hallmarks when determining the choice of first-line treatment in NP. ${ }^{15,16}$

\section{Methodology}

A multidisciplinary expert panel of five pain specialists (pharmacologist, clinical researcher, two pain physicians and a neurologist) in this article reports an expert consensus on topical approaches that may be recommended to alleviate LNP and on their advantages in clinical practice. The literature search was performed using Medline from 2010 to December 2016, and all studies involving LNP physiopathology and treatments were examined. Keywords were "neuropathic pain, localized pain, lidocaine, plaster, capsaicin, topical drug, pharmacology, pain relief"; 200 articles ( $80 \%$ reviews) were identified and read, and the results are now presented.

\section{Prevalence of LNP}

Estimation of NP prevalence in the general population ranges from $3 \%{ }^{17}$ to $6.9 \%,{ }^{6} 8 \%,{ }^{18} 9 \%,{ }^{19,20} 9.3 \%{ }^{21}$ to $9.8 \%{ }^{22}$ LNP represents the bulk of NP and accounts for $60 \%$ of NP conditions. ${ }^{14}$

\section{Etiology of LNP}

LNP may have different origins. It may be related to an infectious disease, as in PHN or AIDS, or be metabolic as in painful DPN, toxic (alcoholic neuropathy) or related to vitamin deficiency (neuropathy due to B12 deficit). A significant proportion of LNP is postsurgical: post-thoracotomy (29\%), post-mastectomy (31\%), cesarean scars $(21.4 \%)$, knee arthroscopy or total knee arthroplasty (11.4\%), saphenectomy $(15.7 \%)$, inguinal hernia repair $(11.4 \%)$, cholecystectomy
(6.1\%), etc. ${ }^{23}$ Nerve entrapment may also lead to LNP in the long term (Morton's neuroma, tarsal and carpal tunnel syndrome, etc). Other pathologies affecting nerve radicellae may lead to LNP: radiculalgia sequelae, low back pain, cervicobrachial neuralgia or cervicobrachial syndrome. Complex regional pain syndrome type $\mathrm{I}$ is another LNP etiology. Finally, LNP may also be of iatrogenic origin: cancer chemotherapy causes pain with neuropathic characteristics, in $25 \%-50 \%$ of patients treated with vinca alkaloids (vincristine), taxanes, platins, bortezomib or epothilone. ${ }^{24}$

\section{Pathophysiology of NP}

The mechanisms underlying NP are not fully known but involve plastic changes in afferent nociceptive fibers from peripheral nerves and central spinal sensory relays, mainly leading to neuronal hyperexcitability. ${ }^{25,26} \mathrm{NP}$ is associated with central sensitization and hyperexcitation of spinal nociceptive neurons inducing increase in spontaneous discharge. In addition, concomitant impairment of modulatory descending inhibitory controls has also been suggested, due to their interactions with afferent fibers and interneurons and projecting neurons in the dorsal horn of the spinal cord $^{27}$ with an imbalance in descending excitations and inhibitions. ${ }^{28}$ A loss of descending inhibitory noradrenaline controls together with a gain of 5-HT3 receptor-mediated facilitations after neuropathy has also been suggested. ${ }^{28}$ The efficacy of descending inhibitory controls has been shown to be significantly reduced with the course of aging, ${ }^{28}$ possibly contributing to a higher frequency of NP in the elderly. LNP is also characterized by peripheral hyperexcitability, with overexpression of sodium and TRPV family 1 channels located on nerve cell membranes. The analgesic action of topical drugs used for NP treatment specifically concerns such channels, which are widely distributed on the surface of superficial/epidermal nociceptive fibers. ${ }^{29,30}$

\section{LNP assessment}

Abnormal sensations related to NP are generally distinguished as positive painful symptoms (spontaneous: shooting pain, tightness, burning sensation or electric shock; evoked: allodynia or hyperalgesia) and negative sensory signs (deficit or complete loss of perception of mechanical, thermal or noxious stimuli), with other concomitant nonpainful symptoms such as paresthesia, unpleasant sensation or numbness. Allodynia is defined as pain following a normally non-painful stimulation and differs from hyperalgesia, an extreme, exaggerated reaction to a stimulus that is normally painful. ${ }^{22}$ 
Community physicians (general practitioners [GPs]) are the first health care professionals that chronic pain patients visit, and pain represents about $40 \%$ of primary care consultations in Western countries. ${ }^{31}$ Referral to a pain clinic or pain specialist is usually made when GPs have tried most treatments at their disposal for a painful condition which becomes chronic. However, only $2 \%$ of chronic pain patients are followed up by a pain specialist. GPs thus need easy-to-use specific tools to avoid missing NP diagnosis and to be able to prescribe appropriate treatment. Several tools have been developed to screen and diagnose NP (Leeds Assessment of Neuropathic Symptoms and Signs, ${ }^{19}$ Douleur Neuropathique 4 questions, ${ }^{32}$ painDETECT, ${ }^{33}$ but their use seems not to be frequent in general practice.

An expert consensus conference, based on a literature survey and analysis identifying articles most relevant to LNP, led to a definition of LNP as "a type of NP characterized by consistent and circumscribed area(s) of maximum pain associated with negative or positive sensory signs and/or spontaneous symptoms characteristic of NP." "14,34

For general practice, a screening tool based on IASP criteria was recently developed to identify LNP in patients with chronic pain. ${ }^{12}$ Experts developed an algorithm using visualized examples to improve early identification of NP and then LNP using simple instruments in nonspecialized clinical practice, in a reliable, easily understood, rapid and hands-on way. Three key questions in the algorithm initially suggest a diagnosis of NP, based on the IASP criteria for NP: 1) check if patient history and history of pain suggest a nerve lesion or disease; 2) check the neuroanatomical plausibility of pain symptom distribution; and 3) proceed with sensory examination to screen for sensory deficits. This is associated with a simple procedure for clinical examination. A final question is pain localization and area, ie, the localized character of NP.

\section{Topical pharmacological treatment of LNP}

Despite continuous improvement in understanding NP pathophysiology, treatment remains difficult. Poor patient compliance is often caused by drug-related adverse events, interactions with concomitant medication and long-term therapy.

Systemic pharmacological treatment of NP has limited efficacy, as only $40 \%$ patients report significant relief. International guidelines are regularly published ${ }^{10-13}$ and recommend antidepressants, antiepileptics or opioids, although these drugs have significant side effects that often limit long-term use. ${ }^{35}$
Transdermal analgesics with systemic action are commonly used in many situations of pain: acute pain (nonsteroidal anti-inflammatory drugs [NSAIDs], fentanyl) or chronic nociceptive pain (fentanyl, buprenorphine). For a strict topical treatment, dermal drug delivery is a noninvasive means acting directly on the skin.

Lidocaine $5 \%$ and capsaicin $8 \%$ plasters have been used for a few years. Their rationale is that pain is transmitted to the central nervous system by afferent nociceptive fibers, and transmission can be interrupted by local application of blocking drugs with no (or extremely limited) systemic effect. Topical 5\% lidocaine-medicated plaster is recommended as first line for NP treatment by recent guidelines based on randomized controlled trials (RCTs). ${ }^{12,36}$ In patients suffering from PHN and HIV neuropathy, capsaicin $8 \%$ cutaneous patch has been rated as level A efficacy by the European Federation of Neurological Societies. ${ }^{37}$

\section{5\% Lidocaine-medicated plaster}

Lidocaine ensures its anesthetic action by irreversibly inhibiting $\mathrm{Na}^{+}$channels. Topical 5\% lidocaine-medicated plaster marketed since 1999 in the USA by Endo Pharmaceuticals (Malvers, PA, USA) as Lidoderm ${ }^{\circledR}$ and since 2007 in the UK by Grünenthal (Aachen, Germany) as Versatis ${ }^{\circledR}$ is indicated for adults in the symptomatic treatment of postherpetic neuralgia.

\section{Mechanism of action and pharmacodynamics}

Topical 5\% lidocaine-medicated plaster acts in two modes: a pharmacological action through lidocaine diffusion and a protective action of the hydrogel plaster itself. Plasters do provide a mechanical barrier against the stimuli causing allodynia or hyperalgesia in patients with NP (rubbing of clothing or inadvertent touching).

Lidocaine acts via nonselective blockade by bonding in the pore of $\mathrm{Na}^{+}$channels on sensory afferents of small damaged or dysfunctional pain fibers at the site of application. ${ }^{38,39}$ This blockade reduces ectopic discharge and signal propagation. Penetration into the intact skin after transdermal diffusion does not produce a complete sensory block of $\mathrm{Na}^{+}$channels on large myelinated $\mathrm{A} \beta$ sensory fibers. ${ }^{38} \mathrm{Na}^{+}$ channel configuration depends on voltage conditions and will influence the binding rate and the affinity of lidocaine..$^{39,40}$

Compared to placebo, lidocaine plaster reduces allodynia and neuropathic symptoms in patients with peripheral painful neuropathy. ${ }^{41-43}$ However, in healthy human volunteers, the lidocaine-medicated plaster induces variable effects on different sensory thresholds, such as for cold, warmth, touch, hot pain and mechanical pain, and on secondary hyperalgesic 
areas following intradermal capsaicin-induced pain (flare, allodynia and hyperalgesia). ${ }^{44,45}$ Reduced allodynia area (50\%) is an important factor that improves the quality of life. ${ }^{46}$

\section{Pharmacokinetics at glance}

The systemically absorbed dose of lidocaine depends on both the area of skin covered by the medicated plaster and the duration of application. About 3\% of the maximum recommended dose of lidocaine (three plasters applied simultaneously for 12 hours) is systemically absorbed (for single or multiple repeated applications), while at least 95\% (665 mg) remains in the applied medicated plaster. Mean peak lidocaine blood concentration is between 0.13 and $0.23 \mu \mathrm{g} / \mathrm{mL}$ (corresponding of one-tenth of the concentration required to treat cardiac arrhythmia). ${ }^{38}$ An important point is that topical lidocaine is associated with low systemic exposure and minimal risk of system toxicity. Lidocaine binds predominantly to alpha-1acid glycoprotein and presumably passes through passive diffusion across the placental and blood-brain barriers. Local skin metabolism is not known, but systemic lidocaine is metabolized in the liver to nonactive metabolites that are excreted by the kidneys. After medicated plaster application in healthy volunteers, the elimination half-life of lidocaine is 7.6 hours and is delayed in case of cardiac, renal or hepatic insufficiency, but a dosage adjustment is not required. ${ }^{47}$

\section{Tolerability, safety and toxicity}

A good tolerability of topical 5\% lidocaine-medicated plaster is generally reported. Its limited systemic diffusion reduces the risk of adverse events and potential interaction with concomitant medications. Pathologies such as hepatic or renal deficiency necessitate dose adjustment to avoid the risk of toxic blood lidocaine concentrations. Such precautions are not necessary in patients with mild or moderate renal or hepatic impairment. Potential risk of additive systemic effects must be taken into account in patients treated with other local anesthetics or Class I antiarrhythmic drugs (eg, mexiletine and tocainide).

Approximately 5\% of patients may experience adverse reactions, but these were similar to control drugs $(5 \%)$ in controlled studies. ${ }^{48}$ In the treatment of DPN and PHN, lidocaine was much better tolerated than the systemic pain medication pregabalin (adverse events rate, 5.8\% with lidocaine-medicated plaster, versus $41.2 \%$ with oral pregabalin; $P<0.0001) .{ }^{49}$ Skin reactions such as pruritus, erythema, burning, rash, edema and dermatitis are the most frequently reported adverse events of lidocaine and are restricted to the medicated plaster application area. These are generally transient and spontaneously resolve within a few minutes to hours after plaster removal.

Finally, 5\% lidocaine-medicated plaster provides sustained pain relief and is well tolerated in long-term use (3-5 years) for NP of different causes. ${ }^{50,51}$

\section{8\% Capsaicin}

A topical patch of $8 \%$ capsaicin (marketed as Qutenza ${ }^{\circledR}$; previously designated NGX-4010) was approved in 2009 by the US Food and Drug Administration (FDA) for the management of NP associated with PHN and by the European Medicines Agency (EMA) in several European countries for use in peripheral NP. ${ }^{52,53}$

\section{Mechanism of action and pharmacodynamics}

Capsaicin interacts with sensory afferents via its selective agonist affinity for the TRPV1, a ligand-gated nonselective cation channel primarily expressed on $\mathrm{A} \delta$ fibers and $\mathrm{C}$ fibers and in intracellular organelles (endoplasmic reticulum). Capsaicin activity is mediated by opening TRPV1 channel followed by depolarization through the influx of $\mathrm{Na}^{+}$and $\mathrm{Ca}^{2+}$ and release of $\mathrm{Ca}^{2+}$ from the endoplasmic reticulum resulting in the propagation of action potentials in nerves within the spinal cord and brain. This results in an experience of warmth, burning or itching. The abnormally high intracellular concentration of $\mathrm{Ca}^{2+}$ induces osmotic swelling and depolymerization of microtubules. Capsaicin selectively blocks small diameter sensory afferent nerves. It does not affect larger diameter afferents that maintain detection of vibratory and mechanical stimuli. The activation of cutaneous nociceptors expressing TRPV1 induces erythema and pungency due to the release of vasoactive neuropeptides such as calcitonin generelated peptide (CGRP) and substance P. Localized functional block of nerve fiber terminals responsive to capsaicin in the epidermis and dermis is fully reversible and caused by loss of mitochondrial function due to Ca overload, causing collapse of nerve endings and reducing the afferent barrage that may underlie localized pain. This process results in substance $\mathrm{P}$ depletion following topical capsaicin application. ${ }^{54,55}$ Subsequent improvement in NP occurs in 6-12 weeks with the use of a single $8 \%$ capsaicin patch. ${ }^{56}$

Mechanisms of action of capsaicin and lidocaine plasters are quite different. While lidocaine acts as an antagonist by blocking $\mathrm{Na}^{+}$channel action potentials with a discontinuous mode of action, capsaicin triggers a cascade of events after an agonist effect on TRPV1 channel, with a continuous effect that may last 3 months. ${ }^{52,53}$ Further research on the long-term effect of both patches on several modalities (pressure, cold, 
warm, etc.) would be interesting to propose predictive factors of topical treatment efficacy.

\section{Pharmacokinetics at glance}

Capsaicin is the primary capsaicinoid causing the spicy flavor of chili pepper fruit. It is a lipophilic water-insoluble compound that penetrates the epidermis (keratinocyte layer), with low transdermal penetration. Capsaicin is not soluble in plasma and is not absorbed into the microvasculature. Each $280 \mathrm{~cm}^{2}$ patch contains $179 \mathrm{mg}$ of capsaicin (640 $\mu \mathrm{g}$ capsaicin $\left./ \mathrm{cm}^{2}\right)$. After 60 -minute application of the $8 \%$ capsaicin patch, plasma concentrations are very low $\left(\mathrm{C}_{\max }=1.38 \mathrm{ng} / \mathrm{mL} ; \mathrm{T}_{\max }=1.46\right.$ hours $) .{ }^{57}$ Capsaicin absorption is affected by duration, site and total area of application. Biodisponibily is much lower when the treatment is applied on the feet in HIV-associated neuropathy or painful DPN than in treatment on the trunk in patients with PHN. ${ }^{57}$ After 60 or 90 minutes of $8 \%$ capsaicin patch application, the apparent volume of distribution is very high $(173,000 \mathrm{~L})$. Drug concentration in breast milk after topical application is not known. ${ }^{58}$ Capsaicin is metabolized by various cytochrome P450 enzymes in human liver, and it is unlikely that its metabolites act on transient receptor potential vanilloid 1 receptor (TRPV1). ${ }^{59}$ In healthy volunteers, elimination halflife of capsaicin after dermal application is 1.64 hours, and drug plasma levels decline very rapidly after patch removal. ${ }^{57}$ Capsaicin is mainly excreted as metabolites by the kidneys and in a small untransformed proportion in feces and urine. ${ }^{60}$

\section{Tolerability, safety and toxicity}

The systemic safety profile of topical capsaicin is optimal, thanks to its low systemic exposure and its rapid elimination half-life after dermal application. Dose adjustment is not required in patients with renal or hepatic impairment. ${ }^{57}$ Due to its low plasma concentrations, it is unlikely that capsaicin alters the systemic metabolism of concomitant medications by inhibiting or inducing CYP enzymes ${ }^{57}$ No additive effects of topical $8 \%$ capsaicin patch on oral medication were found in patients with PHN. ${ }^{61}$ The principal adverse effects are transitory localized skin reactions such as burning, itching and erythema, caused by the release of substance $\mathrm{P}$ and subsequent stimulation of afferent $\mathrm{C}$-fibers.

It is clear that special care is needed in using topical analgesic agents in elderly and pediatric populations, due to lower ability to metabolize the drugs rapidly and to thinner skin, liable to increase absorption.

Very little information is available concerning the use of lidocaine and capsaicin patches in pregnant women. ${ }^{62}$
Although systemic effects are presumably minimal, women have to be carefully followed up during pregnancy and after childbirth. $^{63}$

Concerning high-concentration topical capsaicin (8\%), a recent Cochrane review ${ }^{64}$ showed more pain relief than control treatment using a much lower concentration of capsaicin, but the quality of the evidence was moderate or very low. Low concentration of capsaicin $(<1 \%)$ applied several times daily over several weeks has no meaningful effect beyond that found in placebo cream. ${ }^{65}$

\section{Other topical agents}

Some other topical treatments for NP have been developed but have not yet been marketed or recommended. $N$-methyl-D-aspartate (NMDA) receptor antagonists are often used in NP management. ${ }^{66}$ Ketamine is a noncompetitive NMDA receptor antagonist that is implicated in central sensitization by lowering the threshold of nerve transduction and reducing central sensitization. ${ }^{67}$ It is commonly used at sub-anesthetic doses as an analgesic, by intravenous route, leading to systemic and psychodysleptic adverse events. Only one randomized, double-blind, placebo-controlled study has been reported, showing the analgesic effect of transdermal ketamine patch ( $25 \mathrm{mg} / 24$ hours) in postsurgical pain following minor procedures. ${ }^{68} \mathrm{~A}$ number of other human randomized controlled studies showed the effectiveness of ketamine as a cream or a gel containing up to $20 \%$ ketamine alone or in combination with other analgesics (such as amitriptyline, baclofen, clonidine or pregabalin). ${ }^{69,70}$ A recent review ${ }^{71}$ showed the effectiveness of topical racemic ketamine in the treatment of several chronic and NP syndromes, and especially in LNP. Despite these findings, topical ketamine is not currently approved for the treatment of NP, and level I RCTs are needed.

Dextromethorphan is another noncompetitive NMDA receptor antagonist, marketed by Home Aide Diagnostics, Inc. (Deerfield Beach, FL, USA) in September 2015 as an external patch (Permavan, NDC\#: 69379-0010-15) for pain relief in a large range of pain (muscle aches and pains as well as arthritis, backache, strain and sprains). This patch, containing trolamine $10 \%$, dextromethorphan $4 \%$ and lidocaine $4 \%$, has not been found to be safe and effective, and it has thus not been approved by the FDA. ${ }^{72}$

The $\mathrm{Na}^{+}$channel blocking local anesthetic bupivacaine has been approved by the FDA as a patch (Eladur ${ }^{\mathrm{TM}}$ ) for nerve block and epidural, intrathecal or regional anesthesia. This long-acting transdermal patch provides a continuous delivery of bupivacaine to the covered area for a period of up 
to 3 days after a single application. Its delivery is comparable to a 12-hour application with topical 5\% lidocaine-medicated plaster. Bupivacaine patch also showed efficacy in PHN in a randomized, double-blind, placebo-controlled study. ${ }^{73,74}$

Diclofenac and ketoprofen are NSAIDs available as patches or creams and have proved effective in some chronic pain conditions, with fewer gastrointestinal adverse effects than with the oral formulation. ${ }^{75-78}$ Although NSAIDs are widely prescribed for NP, ${ }^{79}$ no randomized placebocontrolled trials have been conducted to assess the efficacy of topical NSAIDs on LNP, and the mechanisms of action of these drugs preclude their use in this indication.

Opioids such as $\mu$-agonist fentanyl and the partial $\mu$-agonist buprenorphine have been approved for local application, given their high lipid solubility and low molecular weight, and have shown their effectiveness in chronic cancer and non-cancer pain. Their use in LNP has not yet been assessed.

Antiepileptics and antidepressants are recommended as first-line oral treatment of NP. Of the various recommended drugs (rivastigmine, rotigotine, amitriptyline, selegiline), only rotigotine (Neupro ${ }^{\circledR}$, approved in 2007 in the USA and Europe) and amitriptyline were assessed as transdermal to treat pain conditions. In a randomized controlled exploratory pilot study, rotigotine transdermal patch (from $4 \mathrm{mg} / 24$ hours up to $16 \mathrm{mg} / 24$ hours) improved chronic pain in Parkinson's disease. ${ }^{80}$ A randomized, double-blind, placebo-controlled study showed that amitriptyline transdermal patch (50 and $100 \mathrm{mmol} / \mathrm{L}$ ) was shown to be effective against pain only in healthy volunteers. ${ }^{81}$ No antiepileptic patches were tested, and no antidepressant or antiepileptic patches are currently available for LNP treatment.

Other drugs may also have a potential analgesic effect. Topical use of beta agonists may decrease substance P-mediated pain or irritation in animals. ${ }^{82}$ Finally, etifoxine, a non-benzodiazepine anxiolytic, potentiates GABAA receptor function and accounts for the long-term reduction in pain symptoms in various NP models. Its topical application in animal on lumbar spinal cord segment confirmed its antinociceptive effect. ${ }^{83}$

In summary, $5 \%$ lidocaine and $8 \%$ capsaicin are the only topical plasters specific to LNP available today. Their use in LNP of various etiologies has been the subject of numerous RCTs, reviews, meta-analyses, observational studies and case reports, and their effectiveness has been widely demonstrated. An international advisory board of pain specialists recently agreed that, irrespective of age and on intact, not broken, atrophic or infected skin, topical analgesic should be used as first-line treatment, according to the patients' preference. ${ }^{84}$ Although reviews ${ }^{36,46,85}$ stress the need for additional controlled clinical trials for both drugs, there is agreement from large clinical practice that these topical plasters are efficacious, with low incidence of adverse events.

\section{Pharmacological advantages of local versus systemic treatment}

The pharmacological advantages of local over systemic treatment are diverse. With local routes, the therapeutic effect extends only to the locally affected area. While the oral route is the most frequently used for a pain medication and one of the most convenient, it puts the patient at risk of adverse effects. ${ }^{76,86}$ This is particularly true for vulnerable patients, and especially older patients with comorbidities and polypharmacy. ${ }^{35,87,88}$ Older patients with or without chronic pain often take drugs (eg, gabapentinoids, opioid agonists, selective norepinephrine reuptake inhibitors, tricyclic antidepressants and $\mathrm{Na}^{+}$channel blockers) causing systemic adverse effects and potential risk of adverse drug-drug interactions. ${ }^{63,89,90}$ These adverse events induced by pharmacokinetic and pharmacodynamic age-related changes (decreased absorption, impaired distribution due to modified composition of body compartments, diminished hepatic metabolism and renal clearance, medication-related adverse effects) increase the risk of gastrointestinal disorders, confusion, sedation and memory loss commonly seen with medications for pain management and lead to poor compliance in frail geriatric populations. ${ }^{91}$ Recent NP treatment guidelines highlight 5\% lidocaine-medicated plaster as a possible first-line treatment for frail and elderly patients. ${ }^{13}$ A recent review of various studies concluded that $5 \%$ lidocaine-medicated plaster and capsaicin $8 \%$ patch were effective in elderly patients with polypharmacy. ${ }^{69}$

One kind of serious adverse event associated with drugs with central effects, and especially antidepressants and antiepileptics used for NP treatment, is cognitive impairment. Pain itself may induce cognitive impairment, partly explained by pain-induced modulation of brain areas mediating attention, cognition, mood factors or fatigue caused by sleep disorders. ${ }^{92,93}$ Drugs also directly impact cognitive impairment in pain patients. Pickering et $\mathrm{al}^{35}$ demonstrated negative impacts on various domains of cognition in PHN patients treated with systemic drugs. The cognitive deficits widely observed in NP patients taking antidepressants are not found with 5\% lidocaine-medicated plaster. In this vulnerable population, topical pain management is an interesting alternative to alleviate pain and maintain cognitive integrity. ${ }^{35}$ 
Another advantage of topical administration is the possibility of combination with other pharmacologic agents acting systemically, so as to achieve an additive or synergistic effect without systemic drug interaction or additional side effects. ${ }^{94}$

In addition to its efficacy and safety, local treatment with lidocaine is easy to administer and shows good patient compliance. The possibility of coupling up to three plasters or trimming the plaster to fit different body sites allows good adaptation to the particular pain site. A clinical trial, in which results analysis is ongoing, ${ }^{95}$ clearly shows excellent patient compliance and efficacy in pain following knee arthroplasty.

While the interest of local treatment has been demonstrated in adults and elderly persons, efficacy of pain relief by lidocaine and capsaicin plasters has not been established in large studies in children. Transdermal lidocaine plasters were assessed in children in four studies. ${ }^{96-99}$ In a review of NP management in children with cancer, a step-by-step approach recommends adding a 5\% lidocaine-medicated plaster to the treatment regimen, cutting the plaster to fit if pain is localized..$^{99}$ However, caution is needed because of the immaturity of some neural systems and of pain pathways undergoing a series of transitional functional states before reaching maturity. ${ }^{100}$ Caution is also needed because of the theoretic risk of systemic absorption of lidocaine and its severe toxic effects in case of accidental mucosal absorption (by rubbing the patch on the eye or sucking on the mixture). The use of capsaicin, recommended in adults, is also restricted in children because of pain during application, a greater risk of absorption in pediatrics and the absence of specific pediatric studies. These products are thus not currently recommended in pediatric populations, due to lack of data on safety and efficacy. ${ }^{101,102}$ They may, however, be an attractive option, given the general reluctance to use systemic analgesics in child pain management. ${ }^{103}$

\section{Expert consensus}

For the past 5-10 years, successive international guidelines have included topical $5 \%$ lidocaine and $8 \%$ capsaicin for LNP treatment. These drugs have received regulatory approval in patients with LNP and are now registered in more than 40 countries. There are, however, differences in the registered indication in several countries.

Some guidelines give only weak recommendations for their use as first-line treatment in LNP, and regulatory authorities have sometimes made partial recommendations concerning etiology: in France, for example, lidocaine plasters are recommended (and fully covered by the national health insurance scheme) only in PHN and not in all LNP etiologies.

In light of the large body of literature published on 5\% lidocaine and $8 \%$ capsaicin, the expert panel considers these plasters as first-line drugs for LNP treatment, especially in older patients and patients with comorbidities and polypharmacy. Regulatory indications in LNP should cover the whole range of etiologies and not be restricted to specific etiologies or pain sites.

Since published controlled studies are heterogeneous, there is a real need for more studies for both drugs. ${ }^{95,104}$ However, available publications already clearly suggest that these drugs show an excellent risk/benefit ratio and that they are safe and well tolerated, and show continuous efficacy in long-term treatment. Lidocaine also significantly reduces allodynia and can be applied easily by the patient.

Although sex differences in pain perception are well acknowledged, ${ }^{105}$ sex-related effectiveness of medical plasters is still missing in the literature.

Finally, a major advantage of both plasters is that they reduce the risk of adverse events, such as cognitive impairment, confusion, somnolence, dizziness or constipation, which often impair the quality of life during NP treatment. They may also be used in combination with other drugs and analgesics with no significant drug-drug interactions.

\section{Author contributions}

This article was written by all authors. Pr Gisèle Pickering, Dr Elodie Martin, Dr Florence Tiberghien, Dr Claire Delorme and Dr Gérard Mick conducted the search strategy for the literature search, ensured the selection for relevant articles and wrote the first draft of the manuscript. The assessment of methodological quality was performed by both Pr Gisèle Pickering and Dr Gérard Mick. Pr Gisèle Pickering, Dr Elodie Martin and Dr Gérard Mick provided revision and final approval of the manuscript. All authors contributed toward data analysis, drafting and critically revising the paper and agree to be accountable for all aspects of the work.

\section{Disclosure}

The authors report no conflicts of interest in this work.

\section{References}

1. Treede R-D, Jensen TS, Campbell JN, et al. Neuropathic pain: redefinition and a grading system for clinical and research purposes. Neurology. 2008;70(18):1630-1635.

2. IASP [webpage on the Internet]. Taskforce on Taxonomy. 2011. [cited Nov 15, 2016]. Available from: http://www.iasp-pain.org/Taxonomy. Accessed July 5, 2017. 
3. Morel V, Joly D, Villatte C, et al. Memantine before mastectomy prevents post-surgery pain: a randomized, blinded clinical trial in surgical patients. PLoS One. 2016;11(4):e0152741.

4. Pickering G, Gavazzi G, Gaillat J, Paccalin M, Bloch K, Bouhassira D. Is herpes zoster an additional complication in old age alongside comorbidity and multiple medications? Results of the post hoc analysis of the 12-month longitudinal prospective observational ARIZONA cohort study. BMJ Open. 2016;6(2):e009689.

5. Gavazzi G, Herpes Zoster and Functional Decline Consortium, Pickering G, Schmader K. Functional decline and herpes zoster in older people: an interplay of multiple factors. Aging Clin Exp Res. 2015; 27(6):757-765.

6. Bouhassira D, Lantéri-Minet M, Attal N, Laurent B, Touboul C. Prevalence of chronic pain with neuropathic characteristics in the general population. Pain. 2008;136(3):380-387.

7. Marchettini $P$, Lacerenza M, Mauri E, Marangoni C. Painful peripheral neuropathies. Curr Neuropharmacol. 2006;4(3):175-181.

8. Brown MR, Ramirez JD, Farquhar-Smith P. Pain in cancer survivors. Br J Pain. 2014;8(4):139-153.

9. Mick G, Correa-Illanes G. Topical pain management with the $5 \%$ lidocaine medicated plaster - a review. Curr Med Res Opin. 2012;28(6): 937-951.

10. Dworkin RH, O'Connor AB, Backonja M, et al. Pharmacologic management of neuropathic pain: evidence-based recommendations. Pain. 2007;132(3):237-251.

11. van Hecke O, Kamerman PR, Attal N, et al. Neuropathic pain phenotyping by international consensus (NeuroPPIC) for genetic studies: a NeuPSIG systematic review, Delphi survey, and expert panel recommendations. Pain. 2015;156(11):2337-2353.

12. Deng Y, Luo L, Hu Y, Fang K, Liu J. Clinical practice guidelines for the management of neuropathic pain: a systematic review. $B M C$ Anesthesiol. 2016;16:12.

13. Finnerup NB, Attal N, Haroutounian S, et al. Pharmacotherapy for neuropathic pain in adults: a systematic review and meta-analysis. Lancet Neurol. 2015;14(2):162-173.

14. Mick G, Baron R, Finnerup NB, et al. What is localized neuropathic pain? A first proposal to characterize and define a widely used term. Pain Manag. 2012;2(1):71-77.

15. Casale R, Symeonidou Z, Bartolo M. Topical treatments for localized neuropathic pain. Curr Pain Headache Rep. 2017;21(3):15.

16. Derry S, Wiffen PJ, Kalso EA, et al. Topical analgesics for acute and chronic pain in adults - an overview of Cochrane reviews. Cochrane Database Syst Rev. 2017;5:CD008609.

17. Berger A, Dukes EM, Oster G. Clinical characteristics and economic costs of patients with painful neuropathic disorders. J Pain. 2004;5(3): 143-149.

18. Yawn BP, Wollan PC, Weingarten TN, Watson JC, Hooten WM, Melton LJ. The prevalence of neuropathic pain: clinical evaluation compared with screening tools in a community population. Pain Med. 2009;10(3):586-593.

19. Bennett M. The LANSS Pain Scale: the Leeds assessment of neuropathic symptoms and signs. Pain. 2001;92(1-2):147-157.

20. Bennett MI, Smith BH, Torrance N, Potter J. The S-LANSS score for identifying pain of predominantly neuropathic origin: validation for use in clinical and postal research. J Pain. 2005;6(3):149-158.

21. Fine PG. Chronic pain management in older adults: special considerations. J Pain Symptom Manage. 2009;38(2 suppl):S4-S14.

22. Baron R, Binder A, Wasner G. Neuropathic pain: diagnosis, pathophysiological mechanisms, and treatment. Lancet Neurol. 2010;9(8): 807-819.

23. Dualé C, Ouchchane L, Schoeffler P, EDONIS Investigating Group, Dubray C. Neuropathic aspects of persistent postsurgical pain: a French multicenter survey with a 6-month prospective follow-up. J Pain. 2014; 15(1):24.e1-24.e20.

24. Golan-Vered Y, Pud D. Chemotherapy-induced neuropathic pain and its relation to cluster symptoms in breast cancer patients treated with paclitaxel. Pain Pract. 2013;13(1):46-52.
25. Kohama I, Ishikawa K, Kocsis JD. Synaptic reorganization in the substantia gelatinosa after peripheral nerve neuroma formation: aberrant innervation of lamina II neurons by Abeta afferents. J Neurosci. 2000; 20(4):1538-1549.

26. Woolf CJ, Thompson SW. The induction and maintenance of central sensitization is dependent on N-methyl-D-aspartic acid receptor activation; implications for the treatment of post-injury pain hypersensitivity states. Pain. 1991;44(3):293-299.

27. Pickering G, Pereira B, Dufour E, Soule S, Dubray C. Impaired modulation of pain in patients with postherpetic neuralgia. Pain Res Manag. 2014;19(1):e19-e23.

28. Bannister K, Patel R, Goncalves L, Townson L, Dickenson AH. Diffuse noxious inhibitory controls and nerve injury: restoring an imbalance between descending monoamine inhibitions and facilitations. Pain. 2015;156(9):1803-1811.

29. Dubin AE, Patapoutian A. Nociceptors: the sensors of the pain pathway. J Clin Invest. 2010;120(11):3760-3772.

30. Marwaha L, Bansal Y, Singh R, Saroj P, Bhandari R, Kuhad A. TRP channels: potential drug target for neuropathic pain. Inflammopharmacology. 2016;24(6):305-317.

31. Mäntyselkä P, Kumpusalo E, Ahonen R, et al. Pain as a reason to visit the doctor: a study in Finnish primary health care. Pain. 2001;89(2-3): 175-180.

32. Bouhassira D, Attal N, Alchaar H, et al. Comparison of pain syndromes associated with nervous or somatic lesions and development of a new neuropathic pain diagnostic questionnaire (DN4). Pain. 2005;114(1-2): 29-36.

33. Freynhagen R, Baron R, Gockel U, Tölle TR. painDETECT: a new screening questionnaire to identify neuropathic components in patients with back pain. Curr Med Res Opin. 2006;22(10):1911-1920.

34. Mick G, Baron R, Correa-Illanes G, et al. Is an easy and reliable diagnosis of localized neuropathic pain (LNP) possible in general practice? Development of a screening tool based on IASP criteria. Curr Med Res Opin. 2014;30(7):1357-1366.

35. Pickering G, Pereira B, Clère F, et al. Cognitive function in older patients with postherpetic neuralgia. Pain Pract. 2014;14(1):E1-E7.

36. de León-Casasola OA, Mayoral V. The topical $5 \%$ lidocaine medicated plaster in localized neuropathic pain: a reappraisal of the clinical evidence. J Pain Res. 2016;9:67-79.

37. Attal N, Cruccu G, Baron R, et al. EFNS guidelines on the pharmacological treatment of neuropathic pain: 2010 revision. Eur J Neurol. 2010;17(9):1113-e88.

38. Gammaitoni AR, Alvarez NA, Galer BS. Safety and tolerability of the lidocaine patch $5 \%$, a targeted peripheral analgesic: a review of the literature. J Clin Pharmacol. 2003;43(2):111-117.

39. Sheets MF, Hanck DA. Molecular action of lidocaine on the voltage sensors of sodium channels. J Gen Physiol. 2003;121(2):163-175.

40. Sheets MF, Hanck DA. Outward stabilization of the S4 segments in domains III and IV enhances lidocaine block of sodium channels. J Physiol. 2007;582(pt 1):317-334.

41. Meier T, Wasner G, Faust M, et al. Efficacy of lidocaine patch $5 \%$ in the treatment of focal peripheral neuropathic pain syndromes: a randomized, double-blind, placebo-controlled study. Pain. 2003;106(1-2): $151-158$

42. Meier T, Faust M, Hüppe M, Schmucker P. Reduktion chronischer Schmerzen bei nichtpostherpetischen peripheren Neuropathien nach topischer Behandlung mit Lidocainpflaster. [Reduction of chronic pain for non-postherpetic peripheral neuropathies after topical treatment with a lidocaine patch]. Schmerz. 2004;18(3):172-178.

43. Rehm S, Binder A, Baron R. Post-herpetic neuralgia: $5 \%$ lidocaine medicated plaster, pregabalin, or a combination of both? A randomized, open, clinical effectiveness study. Curr Med Res Opin. 2010;26(7): 1607-1619.

44. Lam VY, Wallace M, Schulteis G. Effects of lidocaine patch on intradermal capsaicin-induced pain: a double-blind, controlled trial. J Pain. 2011;12(3):323-330. 
45. Krumova EK, Zeller M, Westermann A, Maier C. Lidocaine patch (5\%) produces a selective, but incomplete block of A $\delta$ and $\mathrm{C}$ fibers. Pain. 2012;153(2):273-280.

46. Baron R, Binder A, Attal N, Casale R, Dickenson AH, Treede R-D. Neuropathic low back pain in clinical practice. Eur J Pain. 2016;20(6): 861-873.

47. emc [webpage on the Internet]. Versatis 5\% Medicated PlasterSummary of Product Characteristics. 2017. Available from: https://www. medicines.org.uk/emc/medicine/19291. Accessed June 21, 2017.

48. Galer BS, Rowbotham MC, Perander J, Friedman E. Topical lidocaine patch relieves postherpetic neuralgia more effectively than a vehicle topical patch: results of an enriched enrollment study. Pain. 1999;80(3):533-538.

49. Baron R, Mayoral V, Leijon G, Binder A, Steigerwald I, Serpell M. $5 \%$ lidocaine medicated plaster versus pregabalin in post-herpetic neuralgia and diabetic polyneuropathy: an open-label, non-inferiority two-stage RCT study. Curr Med Res Opin. 2009;25(7):1663-1676.

50. Navez ML, Monella C, Bösl I, Sommer D, Delorme C. 5\% lidocaine medicated plaster for the treatment of postherpetic neuralgia: a review of the clinical safety and tolerability. Pain Ther. 2015;4(1):1-15.

51. Wilhelm IR, Tzabazis A, Likar R, Sittl R, Griessinger N. Long-term treatment of neuropathic pain with a $5 \%$ lidocaine medicated plaster. Eur J Anaesthesiol. 2010;27(2):169-173.

52. McCormack PL. Capsaicin dermal patch: in non-diabetic peripheral neuropathic pain. Drugs. 2010;70(14):1831-1842

53. Haanpää M, Treede R-D. Capsaicin for neuropathic pain: linking traditional medicine and molecular biology. Eur Neurol. 2012;68(5):264-275.

54. Sawynok J. Topical and peripherally acting analgesics. Pharmacol Rev. 2003;55(1):1-20.

55. Anand P, Bley K. Topical capsaicin for pain management: therapeutic potential and mechanisms of action of the new high-concentration capsaicin 8\% patch. Br J Anaesth. 2011;107(4):490-502.

56. Derry S, Lloyd R, Moore RA, McQuay HJ. Topical capsaicin for chronic neuropathic pain in adults. Cochrane Database Syst Rev. 2009;(4): CD007393.

57. Babbar S, Marier J-F, Mouksassi M-S, et al. Pharmacokinetic analysis of capsaicin after topical administration of a high-concentration capsaicin patch to patients with peripheral neuropathic pain. Ther Drug Monit. 2009;31(4):502-510

58. Thomson, Micromedex. Drug Information for the Health Care Professional. Vol. 1. Greenwood Village, CO: Thomson/MICROMEDEX; 2006.

59. Walpole CS, Wrigglesworth R, Bevan S, et al. Analogues of capsaicin with agonist activity as novel analgesic agents; structure-activity studies. 1. The aromatic “A-region”. J Med Chem. 1993;36(16):2362-2372.

60. Reyes-Escogido Mde L, Gonzalez-Mondragon EG, VazquezTzompantzi E. Chemical and pharmacological aspects of capsaicin. Molecules. 2011;16(2):1253-1270.

61. Irving GA, Backonja M, Rauck R, Webster LR, Tobias JK, Vanhove GF. NGX-4010, a capsaicin 8\% dermal patch, administered alone or in combination with systemic neuropathic pain medications, reduces pain in patients with postherpetic neuralgia. Clin J Pain. 2012;28(2): 101-107.

62. Ladjevic NG, Likic-Ladjevic IS. Topical glycopirrolate for the management of hyperhidrosis in herpetic neuralgia. Yonsei Med J. 2009 50(2):293-295.

63. Haanpää ML, Gourlay GK, Kent JL, et al. Treatment considerations for patients with neuropathic pain and other medical comorbidities. Mayo Clin Proc. 2010;85(3 Suppl):S15-S25.

64. Derry S, Rice AS, Cole P, Tan T, Moore RA. Topical capsaicin (high concentration) for chronic neuropathic pain in adults. Cochrane Database Syst Rev. 2017;1:CD007393.

65. Derry S, Moore RA. Topical capsaicin (low concentration) for chronic neuropathic pain in adults. Cochrane Database Syst Rev. 2012;(9): CD010111.

66. Lodge D. The history of the pharmacology and cloning of ionotropic glutamate receptors and the development of idiosyncratic nomenclature. Neuropharmacology. 2009;56(1):6-21.
67. Ilkjaer S, Dirks J, Brennum J, Wernberg M, Dahl JB. Effect of systemic $\mathrm{N}$-methyl-D-aspartate receptor antagonist (dextromethorphan) on primary and secondary hyperalgesia in humans. Br J Anaesth. 1997; 79(5):600-605.

68. Azevedo VM, Lauretti GR, Pereira NL, Reis MP. Transdermal ketamine as an adjuvant for postoperative analgesia after abdominal gynecological surgery using lidocaine epidural blockade. Anesth Analg. 2000; 91(6):1479-1482.

69. Sawynok J. Topical analgesics for neuropathic pain: preclinical exploration, clinical validation, future development. Eur J Pain. 2014;18(4): $465-481$.

70. Anitescu M, Benzon HT, Argoff CE. Advances in topical analgesics. Curr Opin Anaesthesiol. 2013;26(5):555-561.

71. Kopsky DJ, Keppel Hesselink JM, Bhaskar A, Hariton G, Romanenko V, Casale R. Analgesic effects of topical ketamine. Minerva Anestesiol. 2015;81(4):440-449.

72. FDA [webpage on the Internet]. Import Alert 66-41. 2016. [cited Nov 14, 2016]. Available from: http://www.accessdata.fda.gov/cms_ia/ importalert_190.html. Accessed July 5, 2017.

73. Bajaj S, Whiteman A, Brandner B. Transdermal drug delivery in pain management. Contin Educ Anaesth Crit Care Pain. 2011;11(2):39-43.

74. Wallace M, Kudrow D, McElveen W, et al. Clinical trial results: a randomized, double-blind, placebo-controlled trial of a three-day bupivacaine patch (ELADUR ${ }^{\mathrm{TM}}$ ) in patients with post-herpetic neuralgia. Poster session presented at: The American Pain Society 27th Annual Meeting; 2008; Tampa, FL.

75. Alessandri F, Lijoi D, Mistrangelo E, Nicoletti A, Crosa M, Ragni N. Topical diclofenac patch for postoperative wound pain in laparoscopic gynecologic surgery: a randomized study. J Minim Invasive Gynecol. 2006;13(3):195-200.

76. Stanos SP, Galluzzi KE. Topical therapies in the management of chronic pain. Postgrad Med. 2013;125(4 Suppl 1):25-33.

77. Jorge LL, Feres CC, Teles VE. Topical preparations for pain relief: efficacy and patient adherence. J Pain Res. 2010;4:11-24.

78. Mazières B. Topical ketoprofen patch. Drugs R D. 2005;6(6):337-344.

79. Ahmed SU, Zhang Y, Chen L, et al. Effect of $1.5 \%$ topical diclofenac on clinical neuropathic pain. Anesthesiology. 2015;123(1):191-198.

80. Rascol O, Zesiewicz T, Chaudhuri KR, et al. A randomized controlled exploratory pilot study to evaluate the effect of rotigotine transdermal patch on Parkinson's disease-associated chronic pain. J Clin Pharmacol. 2016;56(7):852-861.

81. Gerner P, Kao G, Srinivasa V, Narang S, Wang GK. Topical amitriptyline in healthy volunteers. Reg Anesth Pain Med. 2003;28(4):289-293.

82. Leclaire J, de Lacharriere O, Breton L, Societe L'Oreal SA. Cosmetic/ pharmaceutical compositions comprising $\beta$-adrenergic agonists/ substance $\mathrm{P}$ antagonists. US patent 5958432. 1999.

83. Juif PE, Melchior M, Poisbeau P. Characterization of the fast GABAergic inhibitory action of etifoxine during spinal nociceptive processing in male rats. Neuropharmacology. 2015;91:117-122.

84. Allegri M, Baron R, Hans G, et al. A pharmacological treatment algorithm for localized neuropathic pain. Curr Med Res Opin. 2016;32(2): 377-384.

85. Derry S, Sven-Rice A, Cole P, Tan T, Moore RA. Topical capsaicin (high concentration) for chronic neuropathic pain in adults. Cochrane Database Syst Rev. 2013;(2):CD007393.

86. Barkin RL. The pharmacology of topical analgesics. Postgrad Med. 2013;125(4 Suppl 1):7-18.

87. Pickering G. Antiepileptics for post-herpetic neuralgia in the elderly: current and future prospects. Drugs Aging. 2014;31(9):653-660.

88. Pickering G, Lussier DA. Neuropathic pain. In: Lussier D, Cruciani R, editors. Pain Management in the Elderly Patient: A Comprehensive Guide to Diagnosis and Treatment. New York: Springer; 2017. In press 2017.

89. Hajjar ER, Cafiero AC, Hanlon JT. Polypharmacy in elderly patients. Am J Geriatr Pharmacother. 2007;5(4):345-351.

90. Priano L, Gasco MR, Mauro A. Transdermal treatment options for neurological disorders: impact on the elderly. Drugs Aging. 2006;23(5): $357-375$. 
91. Casale R, Mattia C. Building a diagnostic algorithm on localized neuropathic pain (LNP) and targeted topical treatment: focus on 5\% lidocainemedicated plaster. Ther Clin Risk Manag. 2014;10:259-268.

92. Seminowicz DA, Davis KD. A re-examination of pain-cognition interactions: implications for neuroimaging. Pain. 2007;130(1-2): $8-13$.

93. Oluigbo CO, Salma A, Rezai AR. Targeting the affective and cognitive aspects of chronic neuropathic pain using basal forebrain neuromodulation: rationale, review and proposal. J Clin Neurosci. 2012;19(9): 1216-1221.

94. Wolfe GI, Barohn RJ. Painful peripheral neuropathy. Curr Treat Options Neurol. 2002;4(3):177-188.

95. Pickering G. Impact of 5\% lidocaine medicated plaster on allodynic symptoms of localized neuropathic pain after knee surgery; 2016. Available from: https://clinicaltrials.gov/ct2/show/NCT02763592?ter $\mathrm{m}=$ pickering+line\&rank=1. NLM identifier: NCT02763592. Accessed July 5, 2017.

96. Frost SG. Treatment of complex regional pain syndrome type 1 in a pediatric patient using the lidocaine patch 5\%: a case report. Curr Ther Res Clin Exp. 2003;64(8):626-629.

97. Nayak S, Cunliffe M. Lidocaine 5\% patch for localized chronic neuropathic pain in adolescents: report of five cases. Paediatr Anaesth. 2008;18(6):554-558.
98. Rasolofo J, Poncelet M, Rousseau V, Marec-Berard P. Efficacité des emplâtres de lidocaïne $5 \%$ sur les douleurs des crises vaso-occlusives chez l'enfant drépanocytaire. [Analgesic efficacy of topical lidocaine for vaso-occlusive crisis in children with sickle cell disease]. Arch Pediatr. 2013;20(7):762-767.

99. Friedrichsdorf SJ, Nugent AP. Management of neuropathic pain in children with cancer. Curr Opin Support Palliat Care. 2013;7(2): 131-138.

100. Fitzgerald M. The development of nociceptive circuits. Nat Rev Neurosci. 2005;6(7):507-520.

101. Sarbacker GB. Topical therapies for chronic pain management: a review of diclofenac and lidocaine. US Pharm. 2015;40(3):35-38.

102. Groninger H, Schisler RE. Topical capsaicin for neuropathic pain \#255. J Palliat Med. 2012;15(8):946-947.

103. Üçeyler N, Sommer C. High-dose capsaicin for the treatment of neuropathic pain: what we know and what we need to know. Pain Ther. 2014;3(2):73-84.

104. Simpson DM, Robinson-Papp J, Van J, et al. Capsaicin 8\% patch in painful diabetic peripheral neuropathy: a randomized, double-blind, placebo-controlled study. J Pain. 2017;18(1):42-53.

105. Mogil JS. Sex differences in pain and pain inhibition: multiple explanations of a controversial phenomenon. Nat Rev Neurosci. 2012; 13(12):859-866.
Drug Design, Development and Therapy

\section{Publish your work in this journal}

Drug Design, Development and Therapy is an international, peerreviewed open-access journal that spans the spectrum of drug design and development through to clinical applications. Clinical outcomes, patient safety, and programs for the development and effective, safe, and sustained use of medicines are the features of the journal, which

\section{Dovepress}

has also been accepted for indexing on PubMed Central. The manuscript management system is completely online and includes a very quick and fair peer-review system, which is all easy to use. Visit http://www.dovepress.com/testimonials.php to read real quotes from published authors. 